\title{
Short communication: Evaluation of commercial meat cultures to inhibit Listeria monocytogenes in a fresh cheese laboratory model
}

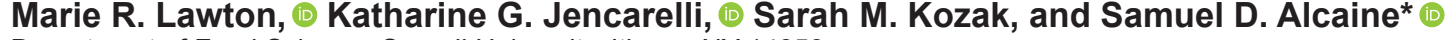 \\ Department of Food Science, Cornell University, Ithaca, NY 14853
}

\section{ABSTRACT}

Control of Listeria monocytogenes in queso fresco and other fresh cheeses continues to be a challenge in the United States. These cheese types are particularly challenging due to their high moisture and high $\mathrm{pH}$, which provide favorable conditions for the growth of $L$. monocytogenes. Protective cultures (i.e., viable strains of lactic acid bacteria that inhibit other microorganisms) have been investigated in foods such as meat as an alternative, clean-label control strategy for L. monocytogenes. However, the efficacy of protective cultures can vary by food matrix. In this study, we were interested in whether protective cultures used to control $L$. monocytogenes in meats could be applied to control the pathogen in queso fresco. We selected 4 commercially available bacterial cultures used for the control of $L$. monocytogenes in meat: Lactobacillus curvatus, Lactobacillus sakei, Pediococcus acidilactici, and Leuconostoc carnosum. We incorporated these cultures into batches of queso fresco during manufacturing and evaluated them for their ability to inhibit the growth of surfaceapplied L. monocytogenes at levels of $1 \times 10^{2}$ and $1 \times$ $10^{4} \mathrm{cfu} / \mathrm{g}$. We stored the queso fresco at 6 and $21^{\circ} \mathrm{C}$ for up to $21 \mathrm{~d}$. After $14 \mathrm{~d}$, Listeria was able to grow to $1 \times$ $10^{7} \mathrm{cfu} / \mathrm{g}$ on the cheese. Our data show that the bacterial cultures did not significantly inhibit the growth of L. monocytogenes in queso fresco. The results from this study highlight the complexity of antagonistic bacterial interactions and their potential variability across food matrices. Protective cultures represent an important, clean-label tool for the control of L. monocytogenes in foods, but each strain must be evaluated in the food environment it is intended for to ensure its efficacy.

Key words: Listeria, lactic acid bacteria, biopreservation, cheese

Received July 2, 2019.

Accepted October 24, 2019.

*Corresponding author: alcaine@cornell.edu

\section{Short Communication}

Listeria monocytogenes is prevalent in the environment and has regularly been isolated in food manufacturing facilities (Kabuki et al., 2004; Ibarra-Sánchez et al., 2017). This organism is an important cause of foodborne outbreaks and can be introduced into readyto-eat food during post-processing if proper hygienic practices are not in place (Kabuki et al., 2004). As well, L. monocytogenes can grow readily in certain ready-toeat dairy products such as fresh cheeses because of their low salt levels, high moisture content, and near-neutral pH (Lin et al., 2006). Eighteen deaths were linked to L. monocytogenes in cheese between 1998 and 2017, according to the United States Centers for Disease Control (CDC) National Outbreak Reporting System. In particular, Latin or Hispanic-style cheeses (e.g., queso fresco) have been the source of many outbreaks (CDC, 2018). Demand for these types of cheeses is growing: the USDA reported the production of over 264 million pounds of Hispanic cheese in 2017 (USDA, 2018). The increasing popularity and consumption of these cheeses highlights the need for improved strategies to control or prevent the contamination and growth of L. monocytogenes in these food products.

The use of lactic acid bacteria (LAB) in food products has been investigated as a clean-label biopreservation method against spoilage and pathogenic microorganisms (Devlieghere et al., 2004). Lactic acid bacteria are naturally present in traditionally fermented foods and have been shown to have antagonistic interactions with other microorganisms present in the food, through direct competition for nutrients, production of antimicrobial products such as bacteriocins or organic acids, or both (Tichaczek et al., 1992; Vogel et al., 1993; Devlieghere et al., 2004). The ability of LAB to inhibit undesirable microorganisms in food has led to some strains being described as "protective cultures."

Protective cultures have been used increasingly in foods as specific controls for L. monocytogenes, particularly in meat products. Several strains of LAB Lactobacillus curvatus, Lactobacillus sakei, Pediococcus acidilactici, and Leuconostoc carnosum-have been 
evaluated for their antilisterial properties in various meat applications, including frankfurters, cooked ham, fermented sausages, chicken cold cuts, and cold-smoked salmon, and have been shown to be effective in reducing or preventing the growth of $L$. monocytogenes without noticeable sensory defects in the products (Amézquita and Brashears, 2002; Katla et al., 2002; Budde et al., 2003; Vermeiren et al., 2004; Benkerroum et al., 2005). Some of these strains, particularly P. acidilactici, $L b$. sakei, and $L b$. curvatus, have been shown to produce bacteriocins with antilisterial activity (Pucci et al., 1988; Nielsen et al., 1990; Tichaczek et al., 1992; Katla et al., 2002).

Given the wealth of available research on these protective cultures, it is perhaps not surprising that strains of Lb. curvatus, Lb. sakei, P. acidilactici, and Leu. carnosum are commercially available for use in high-risk ready-to-eat meat applications. As for many of these meats, controlling the post-processing contamination of high-risk cheese such as queso fresco by L. monocytogenes is a challenge (Moreno-Enriquez et al., 2007; Jackson et al., 2011). Interestingly, published work investigating the ability of these meat cultures to protect high-risk cheese is scarce. In this study, we took 4 commercial protective cultures available for the control of L. monocytogenes in meats, each representing 1 of the 4 species (Lb. curvatus, Lb. sakei, P. acidilactici, and Leu. carnosum), and evaluated their ability to inhibit the growth of surface-applied L. monocytogenes during storage at $6^{\circ} \mathrm{C}$ to reflect average consumer refrigeration temperature, and $21^{\circ} \mathrm{C}$ to reflect accelerated shelf life.

We obtained strains of each culture ( Lb. curvatus, Lb. sakei, P. acidilactici, and Leu. carnosum) from a commercial supplier. Each strain was propagated on de Man, Rogosa, and Sharpe (MRS) agar (Becton, Dickinson, and Co., Franklin Lakes, NJ) at $30^{\circ} \mathrm{C}(L b$. curvatus, Lb. sakei, and Leu. carnosum) or $40^{\circ} \mathrm{C}$ (P. acidilactici) for $48 \mathrm{~h}$ from a frozen glycerol stock. Individual colonies of each strain were inoculated into 5 $\mathrm{mL}$ of MRS broth (Becton, Dickinson, and Co.) and incubated at 30 or $40^{\circ} \mathrm{C}$ for $24 \mathrm{~h}$. Then, $1 \mathrm{~mL}$ of each culture optical density $=1.5$ ) was centrifuged at 1,538 $\times g$ for $4 \mathrm{~min}$, and the resulting pellet was resuspended in $1 \mathrm{~mL}$ of UHT pasteurized skim milk (Parmalat USA Corp., Grand Rapids, MI). The suspension was then transferred to a culture tube containing $9 \mathrm{~mL}$ of UHT milk. Cultures were further incubated at 30 or $40^{\circ} \mathrm{C}$ for $48 \mathrm{~h}$ to achieve a final concentration of 7 to $8 \log \mathrm{cfu} /$ $\mathrm{mL}$, which was confirmed with dilution and plating on MRS agar during each experiment.

Five strains of L. monocytogenes representing 4 outbreak strains linked to fresh cheese (FSL R9-5621, FSL R9-5623, FSL R9-5624, and FSL R9-5625) and 1 internal laboratory strain (FSL X1-0001), were ob- tained from Dr. Wiedmann's Food Safety Laboratory at Cornell University (Ithaca, NY); they can be accessed through www.foodmicrobetracker.com. Each strain was propagated on brain heart infusion (BHI) agar (Becton, Dickinson and Co.) at $37^{\circ} \mathrm{C}$ for $24 \mathrm{~h}$. We then used an individual colony from each strain to separately inoculate $5 \mathrm{~mL}$ of BHI broth (Becton, Dickinson and Co.). The cultures were grown overnight with shaking $(200 \mathrm{rpm})$ at $37^{\circ} \mathrm{C}$. Then, each culture was diluted 1:10 and 1:100, and both dilutions were grown at 30 and $37^{\circ} \mathrm{C}$ with shaking $(200 \mathrm{rpm})$ for approximately $8 \mathrm{~h}$. The cultures closest to and optical density at $600 \mathrm{~nm}=1.00(9 \log \mathrm{cfu} / \mathrm{mL}$ based on previous standard curves for these strains) were used to create a cocktail containing approximately equal amounts of each strain. The cocktail was then serially diluted to achieve the desired inoculum concentration of either 2 $\log \mathrm{cfu} / \mathrm{g}$ or $4 \mathrm{log} \mathrm{cfu} / \mathrm{g}$. The initial inoculum cocktail was also diluted and spread-plated on BHI and modified Oxford (MOX) agar (Becton, Dickinson, and Co.) for enumeration to confirm the starting concentration. Plates were incubated at $30^{\circ} \mathrm{C}$ for $48 \mathrm{~h}$.

Cheese was prepared on a laboratory scale as follows, with guidance from previously established protocols (Van Tassell et al., 2015; Henderson et al., 2019). For each treatment, $600 \mathrm{~mL}$ of nonhomogenized whole milk was brought to $35^{\circ} \mathrm{C}$ in $1 \mathrm{~L}$ sterile bottles. To each bottle, the following were added: $804 \mu \mathrm{L}$ of a 32 to $33 \% \mathrm{CaCl}_{2}$ solution (Dairy Connection Inc., Madison, $\mathrm{WI}) ; 6 \mathrm{~mL}$ of a 7 to $8 \mathrm{log} \mathrm{cfu} / \mathrm{mL}$ LAB culture; and $90 \mu \mathrm{L}$ of double-strength rennet (Chy-Max Extra; Chr. Hansen, Milwaukee, WI) brought to a final volume of $6 \mathrm{~mL}$ in deionized water. The bottles were swirled to mix, and then the mixture was poured into individual plastic cheese vats. The vats were then incubated for $45 \mathrm{~min}$ in a $35^{\circ} \mathrm{C}$ water bath. The curd was cut and the vats were incubated for $15 \mathrm{~min}$ at $35^{\circ} \mathrm{C}$, with a gradual increase to a final temperature of $40^{\circ} \mathrm{C}$. Then, $60 \mathrm{~mL}$ of whey was taken out of each vat and replaced with $60 \mathrm{~mL}$ of an aqueous $\mathrm{NaCl}$ solution $(0.16 \mathrm{~g} / \mathrm{mL})$ and stirred to mix. The vats were incubated at $40^{\circ} \mathrm{C}$ for another $20 \mathrm{~min}$. The whey was then drained from the vats with cheesecloth for $1 \mathrm{~h}$. The curd was then scooped into 12-well plates (Corning Inc., Corning, NY), adding $6 \mathrm{~g}$ of curd to each well. The curd was then pressed for $2 \mathrm{~h}$, giving a final cheese with a weight of approximately $4 \mathrm{~g}$. The $\mathrm{pH}$ of each treatment was measured using an InLab Surface $\mathrm{pH}$ probe (Mettler Toledo LLC, Columbus, OH) and the moisture content was measured using a Smart Turbo Moisture Analyzer (CEM Corp., Matthews, NC). Each measurement was taken in duplicate for each treatment and each batch. Cheeses were prepared in duplicate for each time point and treatment in at least 3 replicates on separate days. 
After pressing, cheeses $(4 \mathrm{~g})$ were surface-inoculated with $100 \mu \mathrm{L}$ of the prepared $L$. monocytogenes cocktail, achieving a final concentration of either 2 or $4 \log$ $\mathrm{cfu} / \mathrm{g}$. Positive controls (inoculated with L. monocytogenes only) and negative controls (no inoculum) were included. Each set of cheeses was incubated at $21^{\circ} \mathrm{C}$ or $6^{\circ} \mathrm{C}$ for 4 or $21 \mathrm{~d}$, respectively.

We enumerated samples on d $0,1,2$, and $4\left(21^{\circ} \mathrm{C}\right.$ incubation) or $\mathrm{d} 0,1,7,14$, and $21\left(6^{\circ} \mathrm{C}\right.$ incubation $)$ for L. monocytogenes and LAB. Each cheese $(4 \mathrm{~g})$ was placed in a sterile Whirl-Pak filter bag (Nasco, Fort Atkinson, WI) and diluted 1:10 (wt/vol) with sterile PBS. Samples were then homogenized using a stomacher set at normal speed for $60 \mathrm{~s}$, and then serially diluted in PBS. Appropriate dilutions were spread-plated on MRS and MOX agar for enumeration. Plates were incubated at $30^{\circ} \mathrm{C}$ for $48 \mathrm{~h}$. A total LAB count was counted on MRS agar and Listeria (round, concave, black colonies) were counted on MOX agar.

All statistical analyses were performed using $\mathrm{R}$ (version 3.5.2; $\mathrm{R}$ Development Core Team, Vienna, Austria). We performed ANOVA and Tukey's honest significant difference test individually for each time point to compare the log differences in Listeria counts between all LAB treatments and the positive control.

The total MRS counts on d 0 and 1 were 5 to $6 \log$ $\mathrm{cfu} / \mathrm{g}$, and L. monocytogenes counts were $2 \log$ or $4 \mathrm{log}$ $\mathrm{cfu} / \mathrm{g}$, indicating that the LAB strains were present and viable in the cheese. For each treatment, L. monocytogenes levels increased throughout the incubation period, resulting in a final concentration of approximately 7 to $8 \log \mathrm{cfu} / \mathrm{g}$ for each temperature and inoculation level. For the higher L. monocytogenes inoculation level of $4 \log \mathrm{cfu} / \mathrm{g}$ at $21^{\circ} \mathrm{C}$ (Figure $1 \mathrm{~A}$ ), no treatment resulted in any significant difference $(P>0.05)$ in $L$. monocytogenes levels compared with the control for any time point. At $6^{\circ} \mathrm{C}$ (Figure $1 \mathrm{~B}$ ) at the same inoculation level, the samples treated with $L b$. curvatus and Lb. sakei showed a significant difference $(P<0.05)$ in L. monocytogenes counts on d 14. However, these counts were only about $0.5 \mathrm{log} \mathrm{cfu} / \mathrm{g}$ lower than the control and did not continue to be significant through the $21 \mathrm{~d}$ of storage. When the cheese was inoculated with a lower concentration of L. monocytogenes (2 log $\mathrm{cfu} / \mathrm{g}$ ), at $21^{\circ} \mathrm{C}$ (Figure $2 \mathrm{~A}$ ) the L. monocytogenes count of the samples treated with $L b$. curvatus displayed a significant difference $(P<0.05)$ from all other treatments and the control on $d 1$. However, the difference was only about $0.5 \log \mathrm{cfu} / \mathrm{g}$. All treatments showed similar L. monocytogenes counts to the control, with no significant differences throughout incubation at $21^{\circ} \mathrm{C}$. At $6^{\circ} \mathrm{C}$ (Figure 2B), Lb. curvatus showed counts about $0.5 \log \mathrm{cfu} / \mathrm{g}$ lower than the control $(P<0.05)$ on $\mathrm{d}$
7 , but by d 21 we found no significant difference $(P>$ $0.05)$ in L. monocytogenes levels.

The $\mathrm{pH}$ of the queso fresco, regardless of treatment, was slightly less than a neutral $\mathrm{pH}$ of 7.0 (Table 1). Typical queso fresco cheeses made in the United States have a $\mathrm{pH}$ above 6.0 , and traditionally the $\mathrm{pH}$ can range from 5.3 to 6.5 , but there is no standard of identity for queso fresco a regulated by the US Food and Drug Administration (Van Hekken et al., 2006; Clark et al., 2009; Ibarra-Sánchez et al., 2017). The negative control and treatments containing LAB were of similar $\mathrm{pH}$ even with the addition of LAB, indicating that the cultures did not produce sufficient amounts of acid to affect $\mathrm{pH}$ during cheesemaking. The moisture content of queso fresco is typically high relative to other cheeses and can range from 41 to 59\% (Clark et al., 2009). This variability in moisture content is the result of manufacturer and consumer preference (Clark et al., 2001; Tunick and Van Hekken, 2010). The queso fresco samples from this study were at the higher end of this range (Table 1). Although the moisture content varied among treatments, the low standard deviation between microbial counts for each treatment and the positive control suggested that the moisture content did not influence microbial growth in this experiment.

Our results suggest that the selected LAB are unable to inhibit the growth of $L$. monocytogenes in a fresh cheese matrix. Although L. monocytogenes counts were reduced compared with the control on certain days, the difference was only about $0.5 \mathrm{log} \mathrm{cfu} / \mathrm{g}$. This reduction was not significant from a biological standpoint and would not be effective as a control strategy. Each of the LAB species have been shown to have antagonistic activity toward L. monocytogenes in media and in meat matrices (Tichaczek et al., 1992; Amézquita and Brashears, 2002; Budde et al., 2003; Vermeiren et al., 2004). However, certain factors could contribute to their contrasting antagonistic behavior in queso fresco. The effectiveness of a strain depends on its ability to adapt to the food matrix and relies on aspects such as $\mathrm{pH}$, moisture, and water activity (Holzapfel et al., 1995). In a study that reported antagonistic activity of Lb. sakei against L. monocytogenes in cooked ham, the ham had a pH close to 6.0, lower than that of the queso fresco used in this study (Vermeiren et al., 2004). Additionally, antimicrobial compounds produced by the LAB, such as bacteriocins, can have limitations depending on the food matrix. For example, binding and interactions to certain food components (such as lipids) can render the bacteriocin ineffective (Holzapfel et al., 1995). A previous study investigating other protective cultures in queso fresco also had unpromising results for the inhibition of L. monocytogenes, showing that after 
a

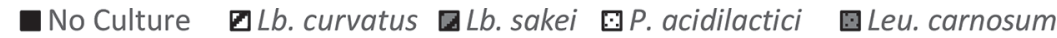
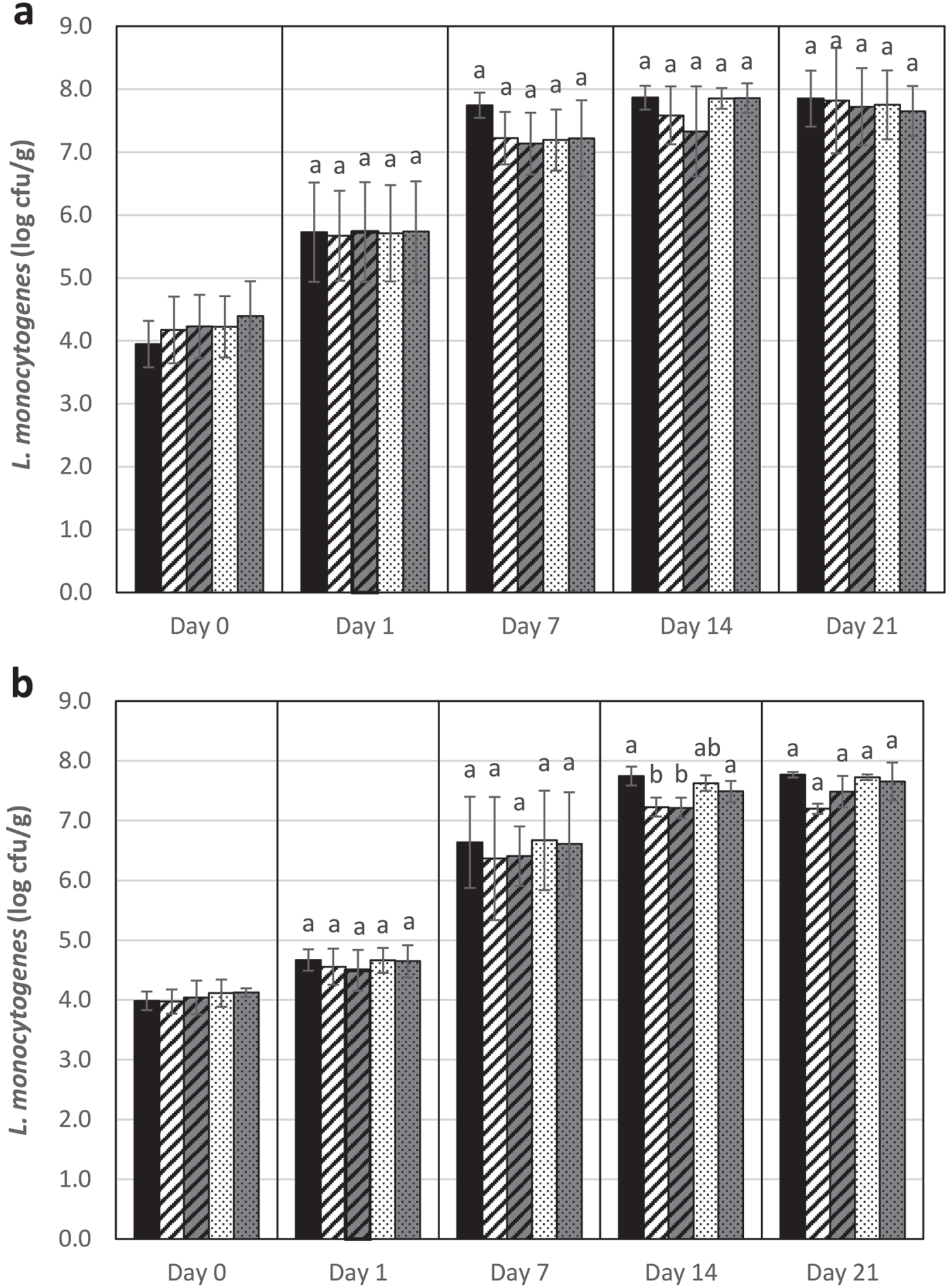

Figure 1. Listeria monocytogenes counts in a laboratory model of queso fresco prepared with protective cultures (Lactobacillus curvatus, Lactobacillus sakei, Pediococcus acidilactici, and Leuconostoc carnosum) and an initial L. monocytogenes load of $10^{4} \mathrm{cfu} / \mathrm{g}$ at (a) $21^{\circ} \mathrm{C}$, and (b) $6^{\circ} \mathrm{C}$. Bars with different letters $(\mathrm{a}, \mathrm{b})$ indicate significant differences $(P<0.05)$ between protective culture treatments on the same day. Error bars represent SD. 
- No Culture $\square$ Lb. curvatus L Lb. sakei $⿴ 囗 ⿱ 一 一)$ P. acidilactici 圆 Leu. carnosum
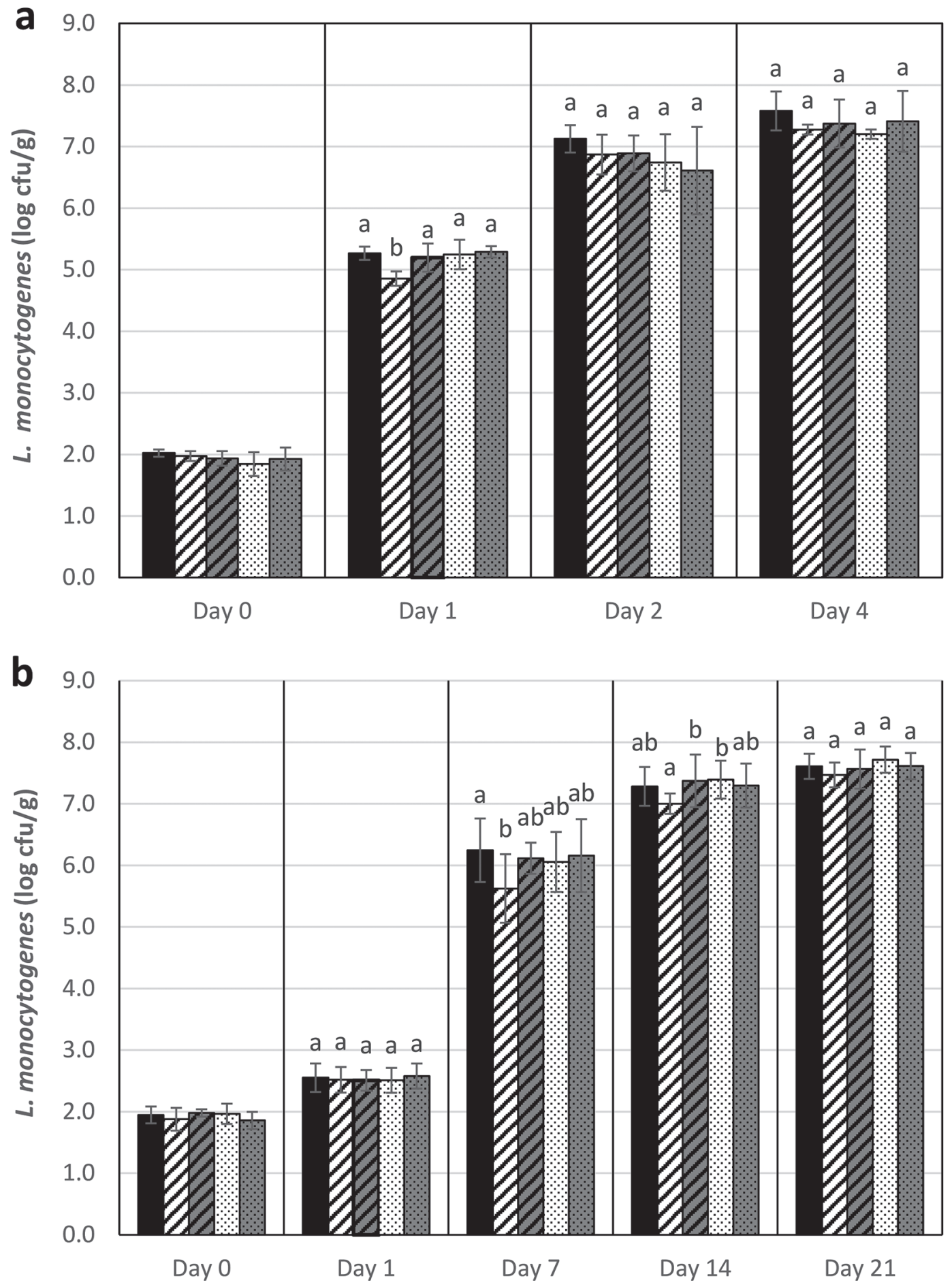

Figure 2. Listeria monocytogenes counts in a laboratory model of queso fresco prepared with protective cultures (Lactobacillus curvatus, Lactobacillus sakei, Pediococcus acidilactici, and Leuconostoc carnosum) and an initial L. monocytogenes load of $10^{2} \mathrm{cfu} / \mathrm{g}$ at (a) $21^{\circ} \mathrm{C}$ and (b) $6^{\circ} \mathrm{C}$. Bars with different letters $(\mathrm{a}, \mathrm{b})$ indicate significant difference $(P<0.05)$ between protective culture treatments on the same day. Error bars represent SD. 
Table 1. Composition of queso fresco samples $( \pm \mathrm{SD})$

\begin{tabular}{lcc}
\hline Culture treatment $^{1}$ & $\begin{array}{c}\text { Moisture } \\
\text { content }(\%)\end{array}$ & $\mathrm{pH}$ \\
\hline No culture & $57.19 \pm 3.02$ & $6.82 \pm 0.29$ \\
Lactobacillus curvatus & $57.72 \pm 1.45$ & $6.68 \pm 0.16$ \\
Lactobacillus sakei & $58.76 \pm 2.22$ & $6.71 \pm 0.16$ \\
Pediococcus acidilactici & $57.95 \pm 2.79$ & $6.68 \pm 0.19$ \\
Leuconostoc carnosum & $58.51 \pm 2.37$ & $6.72 \pm 0.24$ \\
Negative control & $58.30 \pm 2.44$ & $6.74 \pm 0.24$ \\
\hline
\end{tabular}

${ }^{1}$ Indicates the protective culture added to the queso fresco. The negative control had no protective culture added and was not challenged with Listeria monocytogenes.

$21 \mathrm{~d}$, L. monocytogenes counts in a cheese containing a strain of Lactococcus lactis were only $0.7 \mathrm{log} \mathrm{cfu} / \mathrm{g}$ lower than the control (Lourenço et al., 2017).

Some studies using other fresh cheeses have shown successful inhibition of $L$. monocytogenes by LAB. For example, several strains of Enterococcus spp. and a bacteriocin-producing Lactococcus lactis strain were evaluated for their antagonistic activity toward $L$. monocytogenes in Pico cheese, a type of Latin-style fresh cheese (Coelho et al., 2014). In that study, several combinations of different strains led to a $5 \mathrm{log} \mathrm{cfu} / \mathrm{g}$ reduction of $L$. monocytogenes after $7 \mathrm{~d}$, and no sensory differences were detected when the cheese inoculated with these strains was given to consumers. Another study found a bacteriostatic effect against L. monocytogenes when several strains of Enterococcus spp. were applied in fresh Minas cheese (Vera Pingitore et al., 2012). Those cultures resulted in a $3 \log$ inhibition in final L. monocytogenes levels and a decrease in $\mathrm{pH}$ to 5.2 after $12 \mathrm{~d}$. These studies suggest that cultures may be more effective when multiple strains are used in combination or if they produce enough acid to lower the $\mathrm{pH}$.

Protective cultures have been effective at inhibiting L. monocytogenes in other cheese types. A study of the antagonistic activity of a bacteriocin-producing Lactococcus lactis strain against L. monocytogenes in cottage cheese saw an initial $1 \mathrm{log} \mathrm{cfu} / \mathrm{mL}$ reduction of $L$. monocytogenes after $24 \mathrm{~h}$, and after $5 \mathrm{~d}$ the levels of $L$. monocytogenes were reduced to below detectable limits (McAuliffe et al., 1999). Although cottage cheese is also considered a fresh cheese, it traditionally has a starter culture for acidification and therefore has a lower pH (5.2) than queso fresco (McAuliffe et al., 1999). Although similar to queso fresco, cottage cheese may be better suited for inhibition of $L$. monocytogenes with protective cultures because of compositional characteristics such as moisture content, salt concentration (which affects water activity), and $\mathrm{pH}$. These parameters are known to play an important role as hurdles for L. monocytogenes outgrowth (Schvartzman et al., 2011), potentially more so when used in combination with hurdles such as protective cultures. The salt, moisture, and $\mathrm{pH}$ of queso fresco is reported to vary widely (Guo et al., 2011), and the composition of the queso fresco in this study (Table 1) was at the high end of those ranges for both moisture and $\mathrm{pH}$, likely representing a worstcase scenario for inhibiting $L$. monocytogenes.

Control of L. monocytogenes contamination continues to be a challenge in queso fresco and other Latinstyle fresh cheeses because of their high $\mathrm{pH}$ and high moisture content. When working with these types of cheeses, control strategies such as protective cultures may not provide a high level of protection; therefore, good manufacturing practices should continue to be a focus to prevent contamination. Compositional traits such as moisture levels, salt content, and $\mathrm{pH}$ are also critical for L. monocytogenes control, and future research is needed to understand the interplay between those factors and protective cultures to more effectively combine these hurdles to control L. monocytogenes in high-risk cheeses. Certain cultures, such as the ones tested here, may be suited for protection against $L$. monocytogenes in applications such as meat, but their efficacy was clearly challenged under the queso fresco conditions in this study.

\section{ACKNOWLEDGMENTS}

The authors thank the National Dairy Council (Rosemont, IL) and the Innovation Center for US Dairy (Rosemont, IL) for their support of this project. The authors also thank the Cornell Food Safety Laboratory (Ithaca, NY) for guidance during cheese manufacturing. The authors have not stated any conflicts of interest.

\section{REFERENCES}

Amézquita, A., and M. Brashears. 2002. Competitive inhibition of Listeria monocytogenes in ready-to-eat meat products by lactic acid bacteria. J. Food Prot. 65:316-325. https://doi.org/10.4315/ 0362-028X-65.2.316.

Benkerroum, N., A. Daoudi, T. Hamraoui, H. Ghalfi, C. Thiry, M. Duroy, P. Evrart, D. Roblain, and P. Thonart. 2005. Lyophilized preparations of bacteriocinogenic Lactobacillus curvatus and Lactococcus lactis ssp. lactis as potential protective adjuncts to control Listeria monocytogenes in dry-fermented sausages. J. Appl. Microbiol. 98:56-63. https://doi.org/10.1111/j.1365-2672.2004.02419.x.

Budde, B. B., T. Hornbæk, T. Jacobsen, V. Barkholt, and A. G. Koch. 2003. Leuconostoc carnosum 4010 has the potential for use as a protective culture for vacuum-packed meats: Culture isolation, bacteriocin identification, and meat application experiments. Int. J. Food Microbiol. 83:171-184. https://doi.org/10.1016/S0168 $-1605(02) 00364-1$.

CDC (Centers for Disease Control and Prevention). 2018. National Outbreak Reporting System. Vol. 2019. Centers for Disease Control and Prevention, Atlanta, GA.

Clark, S., M. Costello, M. Drake, and F. Bodyfelt. 2009. The Sensory Evaluation of Dairy Products. Springer, New York, NY. 
Clark, S., H. Warner, and L. Luedecke. 2001. Acceptability of Queso Fresco cheese by traditional and nontraditional consumers. Food Sci. Technol. Int. 7:165-170. https://doi.org/10.1177/ 108201320100700210.

Coelho, M. C., C. C. G. Silva, S. C. Ribeiro, M. L. N. E. Dapkevicius, and H. J. D. Rosa. 2014. Control of Listeria monocytogenes in fresh cheese using protective lactic acid bacteria. Int. J. Food Microbiol. 191:53-59. https://doi.org/10.1016/j.ijfoodmicro.2014.08.029.

Devlieghere, F., L. Vermeiren, and J. Debevere. 2004. New preservation technologies: Possibilities and limitations. Int. Dairy J. 14:273-285. https://doi.org/10.1016/j.idairyj.2003.07.002

Guo, L., D. L. Van Hekken, P. M. Tomasula, J. Shieh, and M. H. Tunick. 2011. Effect of salt on the chemical, functional, and rheological properties of Queso Fresco during storage. Int. Dairy J. 21:352-357. https://doi.org/10.1016/j.idairyj.2010.12.009.

Henderson, L. O., L. A. Cabrera-Villamizar, J. Skeens, D. Kent, S. Murphy, M. Wiedmann, and V. Guariglia-Oropeza. 2019. Environmental conditions and serotype affect Listeria monocytogenes susceptibility to phage treatment in a laboratory cheese model. J. Dairy Sci. 102:9674-9688. https://doi.org/10.3168/jds.2019-16474.

Holzapfel, W. H., R. Geisen, and U. Schillinger. 1995. Biological preservation of foods with reference to protective cultures, bacteriocins and food-grade enzymes. Int. J. Food Microbiol. 24:343-362. https: //doi.org/10.1016/0168-1605(94)00036-6.

Ibarra-Sánchez, L. A., M. L. Van Tassell, and M. J. Miller. 2017. Invited review: Hispanic-style cheeses and their association with Listeria monocytogenes. J. Dairy Sci. 100:2421-2432. https://doi .org/10.3168/jds.2016-12116.

Jackson, K. A., M. Biggerstaff, M. Tobin-D'Angelo, D. Sweat, R. Klos, J. Nosari, O. Garrison, E. Boothe, L. Saathoff-Huber, L. Hainstock, and R. P. Fagan. 2011. Multistate outbreak of Listeria monocytogenes associated with Mexican-style cheese made from pasteurized milk among pregnant, Hispanic women. J. Food Prot. 74:949-953. https://doi.org/10.4315/0362-028X.JFP-10-536.

Kabuki, D. Y., A. Y. Kuaye, M. Wiedmann, and K. J. Boor. 2004. Molecular subtyping and tracking of Listeria monocytogenes in Latinstyle fresh-cheese processing plants. J. Dairy Sci. 87:2803-2812. https://doi.org/10.3168/jds.S0022-0302(04)73408-6.

Katla, T., T. Møretrø, I. Sveen, I. Aasen, L. Axelsson, L. Rørvik, and K. Naterstad. 2002. Inhibition of Listeria monocytogenes in chicken cold cuts by addition of sakacin P and sakacin P-producing Lactobacillus sakei. J. Appl. Microbiol. 93:191-196. https://doi .org/10.1046/j.1365-2672.2002.01675.x.

Lin, C.-M., L. Zhang, M. P. Doyle, and B. Swaminathan. 2006. Comparison of media and sampling locations for isolation of Listeria monocytogenes in queso fresco cheese. J. Food Prot. 69:2151-2156. https://doi.org/10.4315/0362-028X-69.9.2151.

Lourenço, A., M. B. Kamnetz, C. Gadotti, and F. Diez-Gonzalez. 2017. Antimicrobial treatments to control Listeria monocytogenes in queso fresco. Food Microbiol. 64:47-55. https://doi.org/10 $.1016 / \mathrm{j}$. fm.2016.12.014

McAuliffe, O., C. Hill, and R. Ross. 1999. Inhibition of Listeria monocytogenes in cottage cheese manufactured with a lacticin 3147-producing starter culture. J. Appl. Microbiol. 86:251-256. https://doi .org/10.1046/j.1365-2672.1999.00663.x

Moreno-Enriquez, R. I., A. Garcia-Galaz, E. Acedo-Felix, H. Gonzalez-Rios, J. E. Call, J. B. Luchansky, and M. E. Diaz-Cinco. 2007. Prevalence, types, and geographical distribution of Listeria mono- cytogenes from a survey of retail queso fresco and associated cheese processing plants and dairy farms in Sonora, Mexico. J. Food Prot. 70:2596-2601. https://doi.org/10.4315/0362-028X-70.11.2596.

Nielsen, J. W., J. S. Dickson, and J. D. Crouse. 1990. Use of a bacteriocin produced by Pediococcus acidilactici to inhibit Listeria monocytogenes associated with fresh meat. Appl. Environ. Microbiol. 56:2142-2145.

Vera Pingitore, E., S. D. Todorov, F. Sesma, and B. D. Gombossy de Melo Franco. 2012. Application of bacteriocinogenic Enterococcus mundtii CRL35 and Enterococcus faecium ST88Ch in the control of Listeria monocytogenes in fresh Minas cheese. Food Microbiol. 32:38-47. https://doi.org/10.1016/j.fm.2012.04.005.

Pucci, M. J., E. R. Vedamuthu, B. S. Kunka, and P. A. Vandenbergh. 1988. Inhibition of Listeria monocytogenes by using bacteriocin PA-1 produced by Pediococcus acidilactici PAC 1.0. Appl. Environ. Microbiol. 54:2349-2353.

Schvartzman, M. S., C. Belessi, F. Butler, P. N. Skandamis, and K. N Jordan. 2011. Effect of $\mathrm{pH}$ and water activity on the growth limits of Listeria monocytogenes in a cheese matrix at two contamination levels. J. Food Prot. 74:1805-1813. https://doi.org/10.4315/0362 -028X.JFP-11-102.

Tichaczek, P. S., J. Nissen-Meyer, I. F. Nes, R. F. Vogel, and W. P. Hammes. 1992. Characterization of the bacteriocins curvacin A from Lactobacillus curvatus LTH1174 and sakacin P from L. sake LTH673. Syst. Appl. Microbiol. 15:460-468. https://doi.org/10 .1016/S0723-2020(11)80223-7.

Tunick, M. H., and D. L. Van Hekken. 2010. Rheology and texture of commercial queso fresco cheeses made from raw and pasteurized milk. J. Food Qual. 33:204-215. https://doi.org/10.1111/j.1745 $-4557.2010 .00331 . x$.

USDA. 2018. Dairy Products 2017 Summary. National Agricultural Statistics Service, Washington, DC.

Van Hekken, D., M. Tunick, J. Renye Jr., and B. G. Vallejo-Cordoba. 2006. Characterization of queso fresco cheeses manufactured in Mexico and the United States. J Dairy Sci. 89(Suppl. 1):313. (Abstr.)

Van Tassell, M. L., L. A. Ibarra-Sánchez, S. R. Takhar, S. L. AmayaLlano, and M. J. Miller. 2015. Use of a miniature laboratory fresh cheese model for investigating antimicrobial activities. J. Dairy Sci. 98:8515-8524. https://doi.org/10.3168/jds.2015-9967.

Vermeiren, L., F. Devlieghere, and J. Debevere. 2004. Evaluation of meat born lactic acid bacteria as protective cultures for the biopreservation of cooked meat products. Int. J. Food Microbiol. 96:149-164. https://doi.org/10.1016/j.ijfoodmicro.2004.03.016

Vogel, R. F., B. S. Pohle, P. S. Tichaczek, and W. P. Hammes. 1993. The competitive advantage of Lactobacillus curvatus LTH 1174 in sausage fermentations is caused by formation of curvacin A. Syst. Appl. Microbiol. 16:457-462. https://doi.org/10.1016/S0723 $-2020(11) 80280-8$

\section{ORCIDS}

Marie R. Lawton () https://orcid.org/0000-0003-0454-2328

Katharine G. Jencarelli @ https://orcid.org/0000-0002-9439-7509

Samuel D. Alcaine $\odot$ https://orcid.org/0000-0001-7953-9145 